\title{
Evaux Thermal Spring Water-based Solution
}

National Cancer Institute

\section{Source}

National Cancer Institute. Evaux Thermal Spring Water-based Solution. NCI Thesaurus.

Code $\mathrm{C} 125898$.

A topical solution containing Evaux thermal spring water, with potential moisturizing and skin protecting activities. Upon application to the nails and surrounding skin, Evaux spring water-based solution forms a film on the nails that serves as a protective barrier. This prevents water loss from, provides moisture to, and strengthens the nails, and protects them from damage. The solution also relieves pain caused by cracked, peeled, thinning or soft nails. Evaux thermal spring water contains the elements lithium, manganese and strontium which may help heal the nails and prevent onycholysis. It also contains chlorphenesin and piroctone olamine, both of which have antifungal activity. Some chemotherapy and/or radiation therapy can induce damage to the nails. 